\title{
Raising awareness of values of space for a sustainable development
}

\author{
I. Garofolo \& E. Marchigiani \\ Department of Architectural and Urban Design, University of Trieste, \\ Italy
}

\begin{abstract}
An educated population is vital when implementing sustainable development, as many UN and EC documents have recently pointed out. This guides the work in progress within the project "R.A.V.E. Space: Raising Awareness of Values of Space through the process of Education", as illustrated in this paper. The project is developed by nine Project Partners within the Interreg IIIB CADSES Programme, and deals with the elaboration of innovative methodologies for the introduction of the concepts of sustainability into regular European educational curricula. The project focuses on the need to develop the attitude to recognize the values of living spaces through a closer observation of relations between space and local communities, giving a particular attention to the reading and interpretation of the material signs of territorial actions aimed to build and/or to take control of space, as well as to the listening to inhabitants' demands, feelings and experiences. The main results of the project foresee, on the one hand, the elaboration of a Strategy for spatial education, on the other hand, the construction of a Manual for teaching the values of space specifically oriented towards the raising of awareness on values of space and sustainable development.

Keywords: education, school curricula, sustainable development, values of space, participation, spatial planning, strategy for spatial education, teaching tools, training workshops, CADSES Programme.
\end{abstract}

\section{Introduction}

The relationship between education, spatial and social integration, and sustainable development is strong and complex, as many UN conferences and EC directives and strategies have pointed out in the past decades, starting from 
the Chapter 36 of Agenda 21 where three main tasks were established: "Re-orienting education towards sustainable development", "increasing public awareness", "Promoting training" [1].

In particular, a subtle combination of higher education, research and life-long learning is felt necessary to shift to a competitive information and knowledgebased economy, which is fuelled less by imported technology and more by local innovation and creativity [2]. To join such an ambitious goal to the growing of social inclusion and cohesion not only a radical transformation of economy is needed, but also a challenging programme for the modernisation of welfare and educational systems [3, 4]. The aim is to spread the knowledge of the manifold issues related to sustainability among a wider public, in order to share the construction and implementation of development processes oriented towards the promotion of a better quality of life.

Defining sustainable spatial strategies through local communities' participation is in particular one of the main issues international agreements such as the European Landscape Convention refer to, whereas effective participation can only start from processes aimed to promote the "increase of awareness among the civil society, private organisations, and public authorities of the value of landscapes, their role and changes to them" [5]. In the Strategy adopted by the United Nations Economic Commission for Europe (UNECE), the tasks of Education for Sustainable Development (ESD) - which subjects are significantly broader than those of environmental education - are similarly highlighted: ESD is seen as "an essential tool for good governance, informed decision-making and the promotion of democracy", since it "can provide critical reflection and greater awareness and empowerment so that new visions and concepts can be explored and new methods and tools developed" [6]. Moreover, the Strategy stresses the importance of international cooperation for the improvement of ESD in different countries as a means for strengthening mutual understanding and respect for cultural values.

The project "R.A.V.E. Space: Raising Awareness of Values of Space trough the Process of Education", funded under the Interreg IIIB CADSES Programme (whereas CADSES stands for Central, Adriatic, Danube and South-Eastern European Space, and the Programme concerns cooperation at a transnational level), directly relates to the aforementioned issues, sharing with the UNECE Strategy the same intent to develop and to merge subjects related to spatial planning and sustainable spatial development into regular educational systems. Sustainability is actually a relevant topic to share and discuss not only by actors in charge of territorial government; indeed, it is an issue which is able to enhance the attention and the involvement both of local communities and of international bodies, also in a context of transnational cooperation helping to overcome any political, administrative, cultural and ethnic borders and obstacles.

\section{The R.A.V.E. Space project}

The R.A.V.E. Space project has a duration of 34 months (from March 2005 to December 2007) and gathers nine partners coming from five different countries 
within the CADSES area: Ministry of the Environment and Spatial Planning (Slovenia, Lead Partner); Department of Geography, Faculty of Arts at the University of Ljubljana (Slovenia); Anton Melik Geographical Institute, Scientific Research Centre of the Slovenian Academy of Sciences and Arts, (Slovenia); Ljubljana Urban Institute (Slovenia); Central European Initiative CEI; Department of Architectural and Urban Design, University of Trieste (Italy); Region of Ionian Islands (Greece); Innovation Foundation (Poland); Bureau for Education Services (Montenegro) [7].

\subsection{General aims}

The project idea is based on the consideration that, in a time of globalisation and quick economic and social changes, spatial planning faces both with higher pressure on land use and with strong demands for protection of natural and cultural resources. In order to promote European citizens' effective influence on spatial development choices, they need deeper awareness and education on the issues of sustainable development.

Spatial planning as a tool for responsible management of the territory should base upon expert decisions and public initiatives; nevertheless, due to the lack of knowledge about the values of space, public generally reacts and takes an active role in planning processes only when its interests are directly menaced, while more often it changes opinion according to more immediate interests or does not participate until spatial decisions are taken and spatial conflicts generated. Such a situation should be overcome with the merging of subjects directly related to the concept of space as a value and a limited resource into the educational process in primary and secondary schools. A better understanding of spatial elements, spatial development and its limitations in fact contributes to thoughtful land use, sustainable development and territorial cohesion, the responsibility of which has to be taken over on a personal and community level. Therefore the R.A.V.E. Space project does not address only to teachers and pupils but also to central and local authorities as well as experts, semi-public and private organisations, with the purpose of providing adjusted educational strategies.

\subsection{Key concepts}

Spreading the knowledge of the values of space among citizens can provide them with the ability and sensibility to actively participate in planning processes, carefully taking into account their future impacts on natural, economic, cultural and social resources. What can be meant for 'values of the space' is however difficult to define.

Values of space are deeply rooted in social practices. When talking about them we thus have to take into account their connection with what is 'imaginative' and 'desired', with 'memory' and 'experience'. In this sense, spatial values can be defined as a system of norms, attitudes, beliefs, standpoints, opinions, perceptions influencing and directing the relations among individuals, space and actions in space. Such a definition points out the importance of interaction between 'objective' and 'subjective' issues and approaches. 
As for the objective issues, space is indeed the supporting ground and the indispensable framework of human dwelling and activity; it is the place where ecological and environmental balance/unbalance between natural and anthropic processes can develop. But it can also be interpreted using the notion of landscape as the perceptual and cultural dimension of space itself. From this point of view we can define space as composed by different types of landscape: urban and suburban, natural and semi-natural. Each landscape is locally characterized by specific spatial components and elements and by specific values: this means that not only historical or natural outstanding places have to be judged as valuable, but also the quality of everyday life open and built spaces must be actively maintained and promoted. This quality strongly refers to the fact that values cannot be judged as 'static'; they are instead the result of processes where people's perceptions and awareness play a fundamental role.

These considerations call for a deeper understanding of subjective issues, due to the manifold factors the relations between space and communities are based on. Values can be recognized only through an attentive observation, which is capable of detecting the material signs of 'territorializing actions' aimed to build/control/use space on one hand, and to listen to the demands, perceptions, memories of the inhabitants on the other.

To 'catch' the values of space perhaps the simplest approach is first to define in which elements of built and open space values take place, then to think about the features characterizing such elements: their physical aspects and their perceptual quality, the materials they are made with and their relations with the surrounding environment and context, their transformations and/or permanence in time, the way they are used and by whom, the relations they have with economic processes, to what extent they are part of local imagination, etc. In this assuming that values of space strongly depend on time (they are not permanent), culture (criteria of value change according to social transformations), scales and modalities of observation, aims of the observer and issues she/he takes as a priority.

The protection and enhancement of the existing values of space (together with the project of new ones) have to be supported by spatial planning, through the drawing of integrated policies and tools working on different scales and topics: from building, to urban and territorial scale; from the conservation of natural resources and historical-cultural features, to the sustainable design of new settlements, to the renewal of the existing ones, etc.

Although territorial planning directly influences the quality of spaces where we all everyday live, people often do not have knowledge of the factors and processes that concur to the construction of the values of the space or that can threaten their existence, of the spheres of action of sustainable development, of the ways and instruments which allow them to participate to planning processes. Carrying in primary and secondary schools in a more explicit way the issues here synthetically recalled can thus represent an important step in feeding the citizens of tomorrow with a more rooted responsibility towards the quality of their living environment and with a deeper knowledge of the ways everybody can contribute to actively promote it [8]. 


\subsection{Activities and expected results}

Activities structuring the R.A.V.E. Space project follow two main working fields.

The first one works at a methodological level. Starting from the analysis of existing curricula and teaching tools at the different levels of school systems in project partners countries, it searches for all spatial related subjects in order to define the most suitable ones for adding new topics referring to such an interdisciplinary concept as values of space. The expected results foresee both the elaboration of educational concepts on sustainable development for primary and secondary schools, and the writing of a document - namely a Strategy for spatial education - closely related to ESD issues.

The second working field stands on a practical level. It focuses on the organization of training activities for teachers and on the elaboration of innovative teaching tools aimed to promote a step by step integration of concepts of sustainable spatial development and of methodologies of participatory planning into the regular educational curricula. These activities are oriented towards the organization of a Summer camp open to teachers and researchers, and to the production of a Manual for teaching the values of space outlining an innovative learning process.

Among the results of the R.A.V.E. Space project there are finally some actions dealing with publicity and dissemination, such as the designing, implementation and updating for the duration of the project of a website, the creation and the distribution within the project partners countries (and in particular in schools and governamental bodies) of posters and brochures, the preparation of a cycle of educational television programes that will be distributed within CADSES and European area.

\section{From analysis of educational systems to a Strategy for spatial education}

According to the above mentioned articulation, the methodological phase of the project included three groups of activities.

Project partners were first asked to go through syllabi and to prepare a table of aims, contents and notions directly or indirectly connected with spatial planning issues. These operations intended to evidence the plurality of subjects useful to introduce the many aspects values of space consist of (from more traditionally spatial related topics such as Geography, to Civil Education, Fine Arts, Sociology, Mathematics, etc.), in order to define which ones better fit for teaching the concepts of sustainable development according to specific ages and levels of education, and to increase pupils' capacity to understand the complex linkage among physical, social, economic and cultural processes spatial planning processes are based on [9].

A second group of activities was dedicated to the organization and carrying out of a survey among primary and secondary school teachers in project partners countries. It allowed one to collect information about the present situation regarding teachers' and pupils' preferences and perceived obstacles, with respect 
to various space related topics and teaching tools included in regular educational process. The survey consisted of five modules: environment as a value for the teacher; learning about spatial development in schools (present situation, preferences and obstacles); the use of different teaching tools; awareness of the values of space among pupils; background information of teachers included in the survey. The findings pointed out some important hints for the further steps of the project: public participation is very important to teachers, but people must be educated to understand the complexity of spatial problems and what possibilities of their active involvement exist; respondents prefer to wait for some 'higher' authority to solve the problems; lack of teaching tools and literature is an important obstacle in presentation of space-related topics; pupils prefer audiovisual methods, didactic games, trips and excursions than verbal ones, and will be more motivated if these kind of methods are used more often [10].

The third group of activities was finally dedicated to the elaboration of a document of addresses for the promotion of spatial education. It was supported by the distribution of a questionnaire among the project partners, asking the prevailing attitudes towards the values of space in the different countries, their relations to spatial planning and educational process. All involved noted in particular a lack of experience in the fields of proactive participatory planning and governance, low grade of respect for formal limitations and regulations in spatial development planning and every day practice, a general absence of educational strategies in the fields of environment, spatial planning, architecture or other similar areas. Starting from these demands for innovation, a first draft of the Strategy for spatial education was prepared. The strategy is intended as a thematic programme planned to be implemented in a clearly defined time frame, which should be used as a base for the preparation of more specific strategies or action plans on national and sub-national level. The aim is that governments admit the importance of basic spatial education and thereby enable educational system, local communities, professional groups, non-governmental organizations and other stake holders to implement education on space values and related themes. By accepting the general strategy and adopting it to the local needs, the governments assure that they will take care for all the necessary conditions for education on space values in primary and secondary schools. This conditions include: long term designation to the program, which must be proved by activities, money and human resources for implementing it; coordination of all the sectors involved in educational process and spatial planning; regular evaluation of reached goals. The strategy proposes many actions, that do not require the establishment of a new subject in schools, such as: stressing the importance of some existent issues, already taught in schools; introducing new, innovative methods and techniques of teaching spatial values (interactive collaboration, solving real-life problems, including professionals at school presentations); involvement of the school building and the school grounds in the process of teaching; cooperation with the local community; active involvement of parents in the school programmes.

In particular, two strategic key themes are highlighted for their capability to raise the awareness of the correlations between spatial issues and sustainable 
development, and to synthesise a variety of educational themes that directly or indirectly relate to subjects from the existing curricula.

- Outdoor learning. Since experiencing and understanding space offers many possibilities for pupils to acquire different kinds of knowledge, it represents a more valuable and flexible teaching tool than more defined, limited and simple methods of teaching in the indoor environment.

- School building design. Teachers should be encouraged to find different ways of extending the role of 'learning environment' towards the means for education. Participation of pupils in maintenance of the school premises (hygiene in the school building and schoolyard, keeping vegetal and animal life in eco-gardens, collection and re-cycling of waste etc.) provides a great opportunity for teaching contents of all subjects, integrating empirical and analytical ways of learning.

A particular importance is finally given by the strategy to the training of teachers, who are supposed to use innovative methods and tools to present the themes related to the values of space and spatial development [11].

\section{From organization of training seminars to a manual for teaching the values of space}

One of the milestones and innovative proposals of the R.A.V.E. Space project is the organization, in each one of the partners' countries, of training seminars for teachers. Their transnational character aims to foster confrontation and mutual enrichment among different educational and cultural realities, and to implement participatory and active learning methods as suggested by a "comprehensive knowledge" approach and by the UNECE Strategy for Education for Sustainable Development. The proposed teaching methodology starts from the evaluation of the awareness of values of space and, through a practical experience, intends to give the students the tools and knowledge for active participation when involved in shared design processes oriented towards sustainable development.

From September 2006 till December 2006 four national seminars were organized, focusing on the common question "How to teach to live spatially". The seminar format consisted of two whole days, including plenary and small working group sessions. Lectures were alternated with practical experience based on exploration, analysis and representation of a local landscape chosen as case study. Seminars were intended as an interactive learning context enhancing mutual exchange, creative thinking, and action oriented learning. The aims were to simulate the possible steps of an interdisciplinary process, in the same way they could be proposed to schoolchildren, as well as to elaborate and experiment new teaching tools and approaches.

The process started with an interactive session oriented towards the achievement - with the help of Brainstorming techniques - of a shared definition of the values of space specifically referring to the local case study. Then, the seminar developed through two main working sessions: 
1. To experience, to observe, to read and interpret. The aim was to raise the knowledge of values of space through the direct observation and experience of them. During the exploration each group particularly focused on one of the values resulted from the brainstorming, following the suggestions of a 'Teacher Trainer' who proposed different approaches and observation/ notation modalities.

2. To elaborate and report, to communicate, to imagine and envision. The aim was to experiment possible methods and teaching aids to help understanding the complexity of the space we live in, the interaction and interdependency of multiple factors and resources (natural, economical, cultural, social, historical), and to highlight strengths and weaknesses, opportunities and threats to the enhancement of values of space and to sustainable spatial development. Each group, helped by the Teacher Trainer, practised different ways to elaborate the direct experience of space made during the exploration, through the use of some specific tools, such as guiding questions to stimulate and focus debate and deeper reflections, and the construction of a Gulliver's Map. Finally, a plenary session was dedicated to the sharing of visions, using participatory methodologies applied to planning processes.

At the end of the seminar, teachers were invited, during the school year, to try out and experiment in their classes the methodologies and teaching tools proposed, working - if possible - together with colleagues teaching different subjects [12]. The further step of this process will be the organization of a Summer Camp in summer 2007 in Italy where teachers, with representatives of all five Countries involved in the project, will work together reporting their experience. The results of the whole training process will be collected in a Manual for teaching the values of space, a tool addressed to teachers and pupils that will be disseminated and made available to Ministries, Regional Departments and other Institution involved with education and sustainable spatial development in CADSES as well as in other European countries.

The contents of the manual will be organized in two sections: the first one describes the concepts related to the definition of values of space and the main techniques suggested to teach them; the second one illustrates a repertoire of teaching units. Teaching units are identified by marks (i.e. number, title and colours), so that teachers who wish to employ them will be able to make up their own learning path, according to different variables: available time during the school year they want to dedicate to this kind of education; level of knowledge/age of pupils; availability or readiness of colleagues to be involved into the educational path; type of context they wish/can explore with the pupils; different kind of materials/supports/founds they can use to develop the teaching process. The units are divided into two groups: those aimed to develop the exploration of a given space, helping and guiding the in-field work according to different issues and approaches (sensorial, analytical, descriptive, experimental); those aimed to develop the in-classroom activities, from elaboration and reporting to envisioning. 
Each teaching unit consists of a chart, with a title referred to the kind of approach it refers to, and is organized into the following sections: introduction and some preliminary notes; aims of the activity; the way to perform it; who is involved as active person; which school subjects the activity can be referred to or have connections with; the suggested duration; the list of required materials to perform it; some suggestions and a more precise description of how to develop the activity. The possibility to bring some changes is also provided, according to the consideration of different in-field conditions, due for example to pupils' different abilities and age, or to the availability of materials which differ from those suggested as the most suitable for the development of the activity itself. In order to make this tool the most adaptable, each chart also includes a white space where teachers can add some notes referring to the actual development of the work in their classroom. The last section is finally dedicated to a selection of bibliographical references and web sites specifically dealing with the suggested approach and techniques.

At the moment, the final number of the teaching units the manual will consist of has not been defined jet. Nonetheless, following the experience carried out during the training seminars, eight different teaching units for exploring space and three concerning the elaboration phase have already been developed. Their charts have been sent to the schools interested into testing them, belonging to four of the countries involved in the project (Italy, Slovenia, Greece, Montenegro). Of course, the results of the testing and their discussion in the Summer camp will help the definition of the final number of units which will form, together with some other material, the 'tool kit' for teachers and pupils representing one of the final outputs of the whole project.

\section{Conclusions}

Values of space should be integral part of education. A better understanding of space values belonging at first to our own everyday living space should be a central part of an educational process, able to help the future generations to make development sustainable. Thus it is crucial to introduce, since the young age, in the permanent education system a way to recognize, appraise and learn about space values. This is one of the aims of R.A.V.E. Space project. What emerged since almost half of the work has been done is that it is not so much important to introduce 'new' school subjects; instead, it is better to organize and implement the current way of teaching subjects directly related to spatial values, introducing, where necessary, a more comprehensive and deep knowledge about causes, effects and processes referring to the development of space and values. The tool kit expected by the R.A.V.E. Space project wishes to be a starting point to think these issues in a more innovative way. The final results of the project strategy and tools to learn and teach to live spatially - will be presented at the Belgrade Conference on ESD on October 2008. 


\section{Acknowledgements}

The paper reports the results of the R.A.V.E. Space project, elaborated through the cooperation among all project partners; in particular, the results described in paragraph 4 belong to WP3 - Teaching Tools processing, of which DPAU of the University of Trieste is responsible and coordinator.

\section{References}

[1] United Nations Conference on Environment and Development (UNCED), Earth Summit: Agenda 21, The United Nations Programme of Action from Rio, United Nations Publications: New York, 1993.

[2] Unesco-ACEID, Educational Innovation for Sustainable Development, UNESCO: Bangkok, 1998.

[3] European Council, Lisbon European Council. Presidency conclusions, Lisbon, 2000.

[4] Commission of the European Communities, Working together for growth and jobs. A new start for the Lisbon strategy, Communication of the Spring European Council, Brussels, 2005.

[5] Council of Europe, European Landscape Convention, Florence, 2000.

[6] United Nations Economic Commission for Europe, UNECE Strategy for Education for Spatial Development, High-level meeting of Environment and Education Ministries, Vilnius, 2005.

[7] R.A.V.E. Space project official website: www.rave-space.org.

[8] Bertolino, S., Demšar Mitrovič, P., Ferluga, C., Fridl, J., Garofolo, I., Kladnik, D., Kušar, S., Marchigiani, E., Nared, J. \& Urbanc, M., Definitions of "Values of Space" and "Sustainable Spatial Development", R.A.V.E. Space project working paper, January 2006.

[9] Resnik Planinc, T. \& Mesec, S., School Curricula and Values of Space, R.A.V.E. Space project working paper, June 2006.

[10] Resnik Planinc, T., Kušar, S., Iglič, H. \& Kovačič, H., Values of Space as an Integral Part of Primary and Secondary Education, R.A.V.E. Space project working paper, September 2006.

[11] Simoneti, M. \& Šorn, M., Strategy for Spatial Education, R.A.V.E. Space project working paper, October 2006.

[12] Bertolino, S., Ferluga, C., Garofolo, I. \& Marchigiani, E., "How to Teach to Live Spatially": Outputs from the Training Seminars, R.A.V.E. Space project working paper, February 2006. 